\title{
The Construction of Car-Sharing Location Index System
}

\author{
Xiong Xiao ${ }^{1, a}$, Xia Jiang ${ }^{1, b}$ and Bin $\mathrm{Ni}^{1, \mathrm{c}}$ \\ ${ }^{1}$ Wuhan University of Technology, management College , China \\ axc2313@qq.com, b1225291642@qq.com, c448102193@qq.com
}

\author{
Keywords: Car-sharing; Location; AHP; Quantitative Research
}

\begin{abstract}
In the increasing car ownership today, car-sharing as a means of rational allocation of resources, is the inevitable trend of social harmony and development. This paper aims to address the important factors that need to be considered in the shared car location. After analyzing the connotation of the car-sharing, the indexes of the location of the shared car are selected, and the index system of the car-sharing is constructed. The fuzzy AHP (F-AHP) is used to evaluate the shared vehicle location. Out of the coordination and socio-economic share of the larger, and gives the coordination of existing public facilities development and the use of long-term benefits to share the proposed car site selection recommendations.
\end{abstract}

\section{Introduction}

Car-sharing is an innovative traffic product service system, and it is a personal mode of transport revolution, which is known as the 21 st century travel mode. In accordance with the international "service economy" theory, car-sharing is through the organization's innovation, improve vehicle use efficiency, so that more consumers get "terminal results" of the service industry innovation. Car sharing in the consumer does not want to buy, and do not have to buy or unable to buy a private car case, through the car to meet the needs of a service to meet the traffic needs. Car sharing is for people who do not need all day car. A private car averaging only 40 minutes a day, 23 hours a day or even more time is idle and take up valuable space venues. We work together to use a car, and improve the efficiency of vehicle resources, save resource consumption, promote Environment-friendly, which is the basic principle of car-sharing [1]. Car Ownership: an enterprise or organization with a variety of models provides car service to its members throughout the day through its fixed parking lot, which is paid only by the time and mileage of the vehicle. The main advantage of car-sharing is its flexibility. For the vast majority of consumers who use cars as motorized tools, when consumers need a car, what he actually needs is the right to use a car rather than a car. Sharing a car for a group of people to provide a shared car, the car can be used only for an hour. It can be the whole weekend, the user can use their own cars, like free to drive [2].

Through car sharing, individuals get the benefits of private cars without having to bear the cost and responsibility of owning cars, and can use a variety of vehicles as needed [3]. The most effective and attractive place for car-sharing is that it can fill the gap between bus and private car use. Different means of transport to adapt to different distances and flexibility. Individual long-distance traffic generally use railways, airplanes, buses or private cars, close traffic can be reached by walking, bicycles, buses, taxis and so on. But for the middle distance of some of the lack of public service traffic, as well as leisure, handling, shopping, traffic inconvenience and other activities with high flexibility, you can use the car to share [4].

\section{Shared Car Evaluation Index System}

The Principle of Constructing Index System. Scientific principles: the construction of the index system must have a certain theoretical basis, which can be able to accurately and objectively reflect the shared car scientific site of the essence.

Feasibility principle: the purpose of the index system is mainly to the development of car-sharing 
evaluation, so to be feasible. In particular, data collection should be convenient and should not be incorporated into the system for data that is not readily available.

Representation principle: the choice of indicators cannot be too much. To be representative, it can accurately reflect the evaluation of the level of development of all aspects of the characteristics of car.

The principle of comparability: The selected indicators should, as far as possible, adopt internationally common names, concepts and calculation methods to be comparable in time and space to facilitate analysis and evaluation of car-sharing development levels in different regions [5] .

Indicator System Selection and Description. At present, the sharing of cars has become a common concern at home and abroad and research hot issues. However, there is still little research on the comprehensive evaluation of the level of shared automobile development, especially the lack of quantitative and qualitative analysis and judgment. This index system is based on the domestic and foreign scholars on the analysis of the level of research on the development of shared car, and in accordance with the above description of the shared car core elements, follow the shared car index system to build the principle of building a measure of shared car development level of comprehensive evaluation Index system [6].

The index system includes three levels: target layer, criterion layer and indicator layer. The second layer of the criterion layer is composed of four levels: demand, economy, coordination, and social and economic efficiency indicators; The third layer of indicators in the above criteria layer to set up a number of evaluation indicators, and ultimately constitute a shared vehicle location index system. By drawing lessons from the relevant research and expert suggestions at home and abroad, the low carbon economic evaluation index was selected, selected and perfected, and finally constructed by 16 indicators of the index system [7]. As shown in Table 1

\section{Shared Car Comprehensive Evaluation}

Standardization of Indicators. As the selection of indicators of data, different dimensions, cannot be directly integrated evaluation, it is necessary to standardize it:

Positive direction of the indicator. For the reverse indicators need to be converted into a positive indicator to measure and compare. In this paper, the reverse index to take its reciprocal to make it positive. $\mathrm{x}{ }^{\prime}=1 / \mathrm{x}, \mathrm{x}$ is the reverse index, and $\mathrm{x}$ ' is the positive index after positive

The dimensionlessness of the index. The positiveness of the indicators results in a large change in the degree of discretization of the individual indicators, and the differences in the dimensions between the indicators make the indicators alienate. In order to make the index value of each index is comparable, this paper uses the range method to carry on the dimensionless processing to each index. $y=\frac{x^{\prime}-x_{\min }}{x_{\max }-x_{\min }}, y$ is the index after dimensionless, $x^{\prime}$ is the positive index of the indicator, $x_{\max }$ and $x_{\min }$ is the maximum and minimum of the individual indicators in each index.

Determine the Weight of the Index. The weight of the evaluation index refers to the relative importance of each evaluation index in the evaluation index system. Whether the setting of the evaluation index is correct and reasonable is necessary to accurately and objectively reflect the low-carbon economic development of the region influences. In this paper, three-scale fuzzy analytic hierarchy process, the three-scale method is a complementary scale, in line with people's thinking logic [10]. Its essence is to measure the comparative relationship between the elements, making the measurement more accurate. The established judgment matrix (priority matrix) is rough, but easy to establish, and the fuzzy matrix transformed by the judgment matrix satisfies the consistency condition, and it is not necessary to carry out the consistency test. And then use the normalization method, we can get the weight of each index, the specific steps are as follows:

Establish a judgment matrix: 


$$
f_{i j}\left\{\begin{array}{c}
1, c(i)>c(j) \\
0.5, c(i)=c(j) \\
0, c(i)<c(j)
\end{array}\right.
$$

$c(i)$ and $c(j)$ in the formula represent the relative importance of $f_{i}$ and $f_{j}$, respectively.

The priority judgment matrix $F=\left(f_{i j}\right)_{m \times n}$ is transformed into a fuzzy consistent matrix $P=\left(\mathrm{p}_{i j}\right)_{m \times n}$, and the fuzzy consistency matrix satisfies the consistency condition. Therefore, it is not necessary to perform the consistency check, and the row is summed and the line is transformed:

$$
\begin{aligned}
& p=\sum_{i=1}^{m} f_{i j}, i=1,2, \mathrm{~L}, m \\
& p_{i j}=\frac{p_{i}-p_{j}}{2 m}+0.5
\end{aligned}
$$

Using the normalization of each index and weight. Fuzzy consistency matrix $P=\left(\mathrm{p}_{i j}\right)_{m \times n}$ The sum of each row of elements (not including their own comparison) and the sum of the diagonal elements:

$$
\begin{aligned}
& I_{i}=\sum_{j=1}^{m} p_{i j}-0.5, i=1,2, \mathrm{~L}, m \\
& \sum_{i} I_{i}=m(m-1) / 2
\end{aligned}
$$

Since $I_{i}$ represents the importance of the index $i$ relative to the upper index, the normalization of $I_{i}$ can be used to obtain the weight of each indicator

$$
w_{i}=I_{i} / \sum_{i} I_{i}=\frac{2 I_{i}}{m(m-1)}
$$

\begin{tabular}{|c|c|c|c|}
\hline $\begin{array}{l}\text { Target } \\
\text { layer }\end{array}$ & Criteria layer & Index layer & $\begin{array}{l}\text { The weight of the } \\
\text { standard }\end{array}$ \\
\hline \multirow{16}{*}{$\begin{array}{l}\text { Share } \\
\text { car } \\
\text { location }\end{array}$} & \multirow{6}{*}{ Demand } & public places & 0.0295 \\
\hline & & Residential area & 0.0295 \\
\hline & & enterprise & 0.0098 \\
\hline & & Travel expenses & 0.0413 \\
\hline & & time & 0.0138 \\
\hline & & Convenience & 0.0138 \\
\hline & \multirow{4}{*}{ Economy } & Vehicle cost & 0.0441 \\
\hline & & Land cost & 0.0441 \\
\hline & & Management costs & 0.0137 \\
\hline & & Technical cost & 0.0238 \\
\hline & \multirow{3}{*}{ Coordination } & Other public transport & 0.0604 \\
\hline & & The overall planning of the city & 0.1584 \\
\hline & & The surrounding site has been built & 0.0692 \\
\hline & \multirow{3}{*}{$\begin{array}{l}\text { Social and economic } \\
\text { benefits }\end{array}$} & Consumer demand to meet the degree of travel & 0.1989 \\
\hline & & The degree of ease of traffic congestion & 0.0759 \\
\hline & & Impact on the natural environment & 0.1738 \\
\hline
\end{tabular}

In this paper, using Delphi method, through the consultation of 20 relevant experts on the index system of the various indicators of the views of the use of the above methods, comprehensive calculation of low carbon economic evaluation index system in the weight of the indicators, as shown in Table 1.

Table 1 share the vehicle location index system 


\section{Comprehensive Evaluation of Indicators.}

Combined with the index weight and dimensionless index, the linear weighting method is used to calculate the comprehensive evaluation index of low carbon economy:

$$
M=\sum_{i=1}^{n} a_{k i} C_{k i}, k=1,2, \mathrm{~L}, m
$$

Where $M$ is the comprehensive evaluation index of shared car location in each region, $a_{k i}$ is the weight of the i-th secondary index in the judgment matrix, and $C_{k i}$ is the weight in the judgment matrix belonging to the k-th item The value of the i-th secondary index of the primary index.

According to the size of M (7) can be a corresponding comparison of the city and the regional layout of the priority of car sharing.

\section{Conclusions}

Sharing the car as a new way of travel, a profound impact on people's travel. As at home and abroad for its research is gradually in-depth, so far cannot be widely promoted [8]. This paper hopes that domestic and foreign scholars will continue to strengthen the discussion on the index system of shared car location, and construct a scientific and reasonable index system as soon as possible so as to provide the correct guiding effect for scientific decision-making of national development and sharing of automobile location.

In addition, this paper compares the weights of each index of the shared vehicle location index system. The coordination and social and economic benefits have a considerable influence on the shared car location. To this end, I suggest from the following two efforts to improve:

Coordinate Existing Facilities. Car license, charging pile, parking spaces and other supporting resources, will restrict the development of shared cars. How to rational allocation of resources, urban road management will put forward new challenges [9]. Related enterprises need to establish a vehicle with the local city to adapt to the mechanism, and local government departments also need to complete the infrastructure in the supporting infrastructure, such as the establishment of the relevant laws and regulations, and the existing means of transport to coordinate the promotion of related industries healthy growth.

Focus on Improving Social and Economic Benefits. Sharing the car market requires the support of consumers, so the degree of consumer demand needs to be improved [10]. According to large data, artificial intelligence and other cutting-edge tools to plan the sharing of car location and delivery, to enhance the degree of consumer satisfaction. In addition, we must take into account the long-term sustainable development, vigorously develop new energy vehicles [11]. If so, we can continuously improve the social and economic benefits.

\section{Acknowledgements}

Wuhan University of Technology independent innovation research fund project, Item Number: 175203004

\section{References}

[1] C. Wu and J.Q. Yang: Communication and Shipping, (2014) No.5, p.33. (In Chinese)

[2] X.Y. Wang: Times Finance, (2014) No.2, p.123. (In Chinese)

[3] X.T. Wang: Journal of Chang' an University (Social Science Edition), (2013) No.4, p39. (In Chinese)

[4] X.Z. Zhou: Logistics Engineering and Management, (2013) No4, p114. (In Chinese)

[5] S.P. Li: Optimization Design of Vehicle Sharing Based on Queuing Theory(Ms., Hangzhou Dianzi University, China 2013), p.28. (In Chinese) 
[6] Q.J. Dai: Journal of Changchun University of Science and Technology (Social Sciences Edition), (2012) No11, p106. (In Chinese)

[7] L.J. Yin, X.D. Wang and Z.Q. Xiong Pioneering with Science \& Technology Monthly, (2010) No10, p98. (In Chinese)

[8] L. Qiu: Research on Market Prospect and Marketing Strategy of Automobile Sharing Service in China (MS., Fudan University, China 2009), p.36. (In Chinese)

[9] Y. Xue, T.Y. Yang and S.B. Wen: Technoeconomics \& Management Research, (2008) No1, p54. (In Chinese)

[10] K.X. Xia, M.S. He and H. Zhang: China Soft Science, (2006) No12, p64. (In Chinese)

[11] H. Li and J.F. Shi: Business Research, (2003) No19, p48. (In Chinese) 